Pilot Study: Combining Formal and Peer Education with FibroScan to Increase HCV Screening and Treatment in Persons who use Drugs Peer-reviewed author version

ARAIN, Amber; De Sousa, Jessica; Corten, Kirsten; Verrando, Rita; THIJS, Herbert; Mathei, Catharina; Buntinx, Frank \& ROBAEYS, Geert (2016) Pilot Study: Combining Formal and Peer Education with FibroScan to Increase HCV Screening and Treatment in Persons who use Drugs. In: JOURNAL OF SUBSTANCE ABUSE TREATMENT, 67, p. 44-49.

DOI: 10.1016/j.jsat.2016.04.001

Handle: http://hdl.handle.net/1942/22568 
Pilot study: Combining formal and peer education with FibroScan to increase HCV screening and treatment in persons who use drugs.

Arain $A^{a, b}$, De Sousa Jb, Corten $K^{b}$, Verrando $R^{c}$, Thijs $H^{d}$, Mathei $C^{e, f}$, Buntinx $F^{g}$, Robaeys $G^{a, b, h}$

aDepartment of Gastroenterology and Hepatology, Ziekenhuis Oost-Limburg, Genk, Belgium ${ }^{\text {FFaculty }}$ of Medicine and Life Sciences, Universiteit Hasselt, Hasselt, Belgium cMedisch Sociaal Opvang Centrum, Genk, Belgium d-BioStat, Universiteit Hasselt, Hasselt, Belgium eFree Clinic, Antwerp, Belgium fDepartment of Public Health and Primary Care KU Leuven, Leuven, Belgium 9Department of General Practice, KU Leuven, Belgium and Maastricht University, The Netherlands hDepartment of Hepatology, University Hospitals KU Leuven, Leuven, Belgium.

Corresponding author: Amber Arain, PhD student, Department of Gastroenterology and Hepatology, Ziekenhuis Oost-Limburg, Schiepse Bos 6, 3600 Genk, Belgium. amber.arain@uhasselt.be

Fax: $+32-89-327916$ 


\title{
Pilot study: Combining formal and peer education with FibroScan to increase HCV screening and treatment in persons who use drugs.
}

\begin{abstract}
Background: Treatment uptake for hepatitis $\mathrm{C}$ virus $(\mathrm{HCV})$ infection remains low in persons who inject drugs (PWID), due to lack of knowledge and low perceived need for treatment. Therefore, we conducted a pilot study to assess the influence on knowledge and willingness for HCV screening and treatment among persons who use drugs (PWUD) by combining formal and peer education with FibroScan measurement.
\end{abstract}

Methods: Clients of the Center for Alcohol and other Drug problems (CAD) in Limburg (Belgium) were randomized into a control group, which received the standard of care, and an intervention group, which received an innovative combination of formal and peer education followed by FibroScan. Knowledge of HCV infection and willingness for screening and treatment were evaluated at baseline, after intervention and 1 and 3 months after intervention by means of questionnaires.

Results: Baseline knowledge was similar for the control $(\mathrm{N}=27)$ and the intervention group $(\mathrm{N}=25)$ ( $58 \%$ vs. $59 \% ; p=0,67)$. Immediately after the information session, knowledge increased to $86 \%$ $(p<0,001)$ in the intervention group. After 3 months, knowledge decreased significantly $(69 \% ; p=0,01)$. No significant changes in knowledge were found in the control group. Baseline willingness for treatment was $81 \%$ in both the control and intervention groups, but after one month decreased in the control group (44\%) and remained stable in the intervention group (75\%). Differences in actual screening uptake between the control and intervention group were not significant (7\% vs. $20 \%)$. Four percent of the intervention group and no one in the control group started treatment.

Conclusion: The small number of subjects should be considered when interpreting the results of this study. In brief, the single information session significantly improved HCV knowledge among PWUD, but did not result in a higher uptake for screening and treatment. This could signify that there are other important reasons, besides lack of knowledge, not to undergo screening or start treatment. The fact that knowledge decreased after 3 months indicates that it would be beneficial to repeat the information session regularly.

KEYWORDS: Hepatitis C Virus; Persons who use drugs; Therapeutic education; Knowledge 


\section{BACKGROUND}

Hepatitis $C$ is a viral infection caused by the hepatitis $C$ virus $(\mathrm{HCV})$ and affects $130-170$ million people worldwide (Denniston, Klevens, McQuillan, \& Jiles, 2012; Fusfeld, et al., 2013). HCV is primarily transmitted through blood-to-blood contact associated with intravenous (IV) drug use. The WHO therefore categorized PWID as the main risk group for infection in western countries and emphasizes the importance of screening and treatment within this population.

However, despite safe and very effective, new treatment options, screening and treatment uptake for HCV infection among PWID remains low. (Solomon, et al., 2015) This could be explained by the many barriers PWID have to overcome, which are related to mistrust of the healthcare system, fear, financial and social status and physical or psychiatric health problems. (Edlin, et al., 2005; Roose, CockerhamColas, Soloway, Batchelder, \& Litwin, 2014) Other important factors are an insufficient knowledge of HCV infection and a low perceived need for treatment. (Mehta, et al., 2008; Zeremski, et al., 2014)

In Belgium, medico-social centers were established in 1997 to provide drug users with accessible medical and psychosocial care to lower the threshold towards making health improving decisions. Previous studies have shown that formal education significantly improved knowledge of HCV (Beste, et al., 2009; Gupta, Romney, Briggs, \& Benker, 2007; Lubega, Agbim, Surjadi, Mahoney, \& Khalili, 2013; Nyamathi, et al., 2010; Proeschold-Bell, et al., 2011; Shah \& Abu-Amara, 2013; Surjadi, Torruellas, Ayala, Yee, \& Khalili, 2011), screening for HCV (Shah \& Abu-Amara, 2013; Skipper, Guy, Parkes, Roderick, \& Rosenberg, 2003), treatment uptake and adherence (Cacoub, et al., 2008; Gupta, et al., 2007; Larrey, et al., 2011; Lubega, et al., 2013) and reduced infection-related risk behavior (Mateu-Gelabert, et al., 2014). Peer education can be used to reach PWUD and to guide them towards screening and treatment. This method already appears to be effective for a number of other chronic diseases such as diabetes, HIV and heart disease. (Geibel, King'ola, Temmerman, \& Luchters, 2012) FibroScan is a fast, non-invasive, painless and therefore patient-friendly method to assess the stiffness of the liver, which is an accurate indication of the stage of liver fibrosis and damage to the liver in persons with hepatitis C viral infection. (Afdhal, et al., 2014)

In short, these studies demonstrate that formal education, peer education and FibroScan assessment can improve HCV-related knowledge and uptake for HCV screening and treatment. 
Therefore we designed an innovative approach by combining formal education, peer education and FibroScan assessment. In this pilot study, one session of formal and peer education was combined with FibroScan to assess the influence on knowledge and willingness for HCV screening and treatment among PWUD attending opioid substitution treatment (OST) program.

\section{PATIENTS AND METHODS}

\subsection{Study population and study center}

Clients of the Center for Alcohol and other Drug problems (CAD) located in Limburg comprise of former and current substance users. CAD is a multidisciplinary center with physicians, social workers, psychologists, psychiatrists and nurses. The center provides OST, but also treats/refers patients for the treatment of other comorbidities. Each year, care is provided to approximately 1300 clients with illegal substance use problems. The population of CAD clients on OST remains stable, however there is some population shifting in and out the program. Every year, approximately $13 \%$ of the clients who left the program for a short time period, reentered the program. A limited number of new clients join the substitution program every year.

The multidisciplinary network to treat substance users with HCV operates as follows: in CAD the addiction care physician (often assisted by a nurse) sends patients' blood to the lab for HCV antibodies and HCV RNA quantitative testing. If the patient is positive for antibodies and HCV RNA they refer the patient to the hepatologist at the nearest hospital, located only three kilometers away from the CAD center. The hepatologist handles further testing/diagnosis such as HCV RNA quantitative test, HCV genotyping, other blood tests, liver biopsy etc., in line with the Belgian reimbursement criteria related to HCV diagnosis and treatment. After each appointment with the hepatologist, the reports are posted to the addiction care physician who referred the patient, because the addiction care physicians also act as general practitioners for these patients and treat them for other comorbidities. Even during the HCV treatment, there is a close collaboration between the hepatologist and the addiction care physician.

Eligible clients were asked to participate in the study during their daily or weekly visit to CAD. The study was conducted between February 2014 and December 2014. At that time interferon based therapy was the standard of care for HCV antiviral therapy in Belgium. The first generation of Direct 
Acting Antivirals (DAAs), telaprevir and boceprevir, were available. Reimbursement for the newer DAAs for HCV infection was approved in Belgium starting on January 1, 2015.

Inclusion criteria for this study included: 1) age $\geq 18$ years, 2) signed informed consent, 3) history of substance use and substitution treatment at CAD Limburg. Exclusion criteria were defined as suffering from cognitive disorders and/or an inadequate knowledge of the Dutch language. Eligible patients were identified by cross-checking the list of the patients attending the substitution program with the care provider. While checking the patient file for eligibility, it was checked whether the patient suffered from a cognitive disorder. In CAD the diagnosis of a cognitive disorder was made by a psychologistpsychiatrist according to the Diagnostic and Statistical Manual of Mental Disorders (DSM-IV) criteria.

This study was approved by the ethical review board of Hasselt University and Ziekenhuis OostLimburg (ZOL).

\subsection{Study design}

For this pilot study, the participants were randomized into two groups: the control group, who received the current standard of care, and the intervention group, who received an information session followed by a FibroScan. The study was single blind, as it was impossible to blind the research team due to the researcher's involvement in the information session and its coordination.

In the control group, it was announced that information brochures on hepatitis $\mathrm{C}$ virus infection were available in the waiting room of the CAD center, which is considered the 'standard of care'. The brochure (supplemental information) available at the CAD provided information about HCV transmission routes, diagnosis, treatment and how to prevent HCV infection.

For the intervention group, information sessions were organized at CAD Limburg in a meeting room with coffee and sandwiches. The information session was organized for small groups with 5 to 10 clients and lasted approximately one hour. Essential information was given by a video and a didactic PowerPoint presentation (supplemental information) in Dutch. The presentation given by the care provider covered the following topics: hepatitis C virus, effects on the liver, disease course, viral transmission, symptoms of hepatitis $C$ infection, diagnosis, prevention of liver damage, treatment for hepatitis $C$ infection and re-infection. After the power point presentation additional information was given by peers who shared personal experiences about the medication, side effects, duration of treatment, costs, family support and the effect of the treatment on their life. Afterwards, there was time 
for questions and discussion. Requirements for being a peer were having successfully completed treatment for HCV infection, having a history of drug use and still being connected to or following the substitution program. These peers previously received a short training on hepatitis $C$ viral infection.

Shortly after the information session, a FibroScan was performed at Ziekenhuis Oost-Limburg, Genk, located on three kilometers from the CAD center. The participation in this study was not affected by the fact that FibroScan could not be performed on site at CAD because the transport to the hospital and the total cost was covered by the study coordinators. The patients were transported by taxi, seating 5-7 passengers, from the CAD to the hospital. Depending on the number of participants, who were scheduled to undergo FibroScan, the study coordinators booked a taxi a couple of days before the visit. The participants were picked up at $C A D$ and brought back afterwards and they were accompanied by a member of the study team. Before the participants underwent the FibroScan, it was explained that this technique is used to measure liver fibrosis. After the FibroScan, the outcome was communicated with the participants and further explanation was given to each participant individually by a hepatologist. Ten valid measurements were performed with a medium (M-) probe.

\subsection{Data collection and statistical analysis}

At baseline, a questionnaire about demographic characteristics was completed. Participants completed a questionnaire assessing HCV knowledge as well as willingness to undergo screening and, if indicated, treatment. This questionnaire was completed at baseline and was repeated immediately after the information session and 1 and 3 months afterwards to assess whether the participants had retained the knowledge over time. This questionnaire consisted of 19 true/false questions regarding HCV-related knowledge (Table 2). The addiction care physician and care workers were contacted to determine whether blood samples were taken from the participants for HCV screening and, if positive, whether they consulted a hepatologist for diagnosis and treatment.

A sample size calculation was not possible because the common standard deviation is not known. Therefore, the rule of thumb for sample size determination in pilot studies was used. This led to 12 participants per group (or 24 in total) that would have to fill in the questionnaires across all three time points. To account for any participants lost to follow-up, as many as possible CAD clients were asked to participate, resulting in a total of 52 participants. 
Patient characteristics were analyzed with descriptive data analysis and summarized using mean \pm SD and frequencies. Patient characteristics were also tested for possible differences between control and intervention groups with Chi square/Fisher's Exact Test. Continuous data that had no normal distribution were shown with median values and interquartile range (IQR). Mann-Whitney U tests were used to assess the differences between the control and intervention groups. To assess the change in knowledge scores over time, a Wilcoxon signed rank test was used. To determine the changes in willingness for a screening test and treatment, a McNemar test was used. A Fisher's Exact Test was performed to test whether being in the intervention group was significantly associated with HCV screening and treatment uptake. A P-value $\leq 0,05$ was considered significant. IBM SPSS Statistics 22 was used to analyze the data.

In order to control for missing data regarding willingness for screening and willingness for treatment, a sensitivity analysis examined the effect in two possible situations. In the first situation all participants with missing data were considered to be willing to receive screening and treatment. In the second situation all participants with missing data were considered not willing to receive screening and treatment.

\section{RESULTS}

Fifty-two clients participated in this study but only 17 completed all questionnaires. Twenty-seven patients were randomized to the control group and 25 to the intervention group. During this study, 7 participants were incarcerated, 2 were hospitalized, 24 left the substitution program and 2 persons died.

\section{Patient characteristics}

Most participants were Belgian males with a mean age of $39 \pm 8$ years. Non-Belgian participants were most frequently of Moroccan (10\%), Turkish (6\%) or Italian (6\%) origin. Fifty-two percent of the total study population graduated from secondary school. Participants most often lived alone in a rented house or flat and received a replacement income with a mean of 959 EUR. Sixty-nine percent of the participants reported that they used drugs intravenously, and $49 \%$ reported that they had injected drugs in the past 3 months. The items that were most often shared when using IV drugs were water $(29 \%)$ and tourniquets (23\%). Sixty-seven percent of the participants were tattooed and $85 \%$ were ever incarcerated. One out of five had received a blood transfusion, but nobody ever received a liver 
transplant. Almost all participants were heterosexual (Table 1). No significant differences in patient characteristics were found between the control and intervention group.

\section{HCV knowledge}

At baseline, the knowledge scores were an average of $58 \%$ for the control group $(n=27)$ and $59 \%$ for the intervention group $(n=25)$ (Table 2). No significant differences were found in baseline knowledge scores between the control and intervention groups $(p=0,67)$ (Figure 1).

Immediately after the information session, average knowledge scores increased by $27 \%(p<0,001)$ to $86 \%$ in the intervention group $(n=25)$ (Figure 1).

One month after the information session knowledge scores (86\%) did not decrease significantly in the intervention group $(n=11, p=0,60)$. After 3 months, knowledge scores $(69 \%)$ decreased significantly in the intervention group $(n=12)$ by $17 \%(p=0,008)$. However, the knowledge scores were still significantly higher than baseline scores $(p=0,02)$. No significant differences in knowledge scores were observed in the control group after one month $(n=11, p=0,14)$ or three months $(n=6 ; p=1)$ (Figure 1).

\section{Willingness to undergo screening and treatment}

At baseline, the majority of the participants were willing to give a blood sample for HCV testing, $89 \%$ (24/27) in the control group and $86 \%(19 / 22)$ in the intervention group. Willingness decreased after one month in the control group from $89 \%(24 / 27)$ to $60 \%(5 / 9)$. In the intervention group, willingness for HCV testing increased from $86 \%(19 / 22)$ to $96 \%(22 / 23)$ after the information session. After one month and after the FibroScan, willingness was 100\% (Table 3). After 3 months, willingness to undergo screening increased in the control group to $67 \%(4 / 6)$, but decreased in the intervention group to $77 \%(10 / 13)$ (Table 3$)$.

In the intervention group the percentage of patients willing to start treatment increased slightly after the intervention (87\%) compared to baseline $(81 \%)$ but there were no significant differences between the different time points. In the control group the number of participants willing to immediately start treatment decreased after one month from $81 \%$ to $44 \%$. At baseline $4 \%$ did not want to start treatment and after one month all participants wanted to consider treatment. After 3 months willingness remained the same in the control group (50\%) but increased in the intervention group (85\%). A 
McNemar test showed no significant changes in willingness for HCV testing or treatment across the different time points (Table 3).

At baseline, 1 month after and 3 months after the intervention there were no significant differences in willingness for screening (baseline $p=1,1$ month after $p=0,08,3$ months after $p=1$ ) and willingness for treatment (baseline $p=0,64,1$ month after $p=0,34,3$ months after $p=0,10$ ) between the 2 groups.

At baseline, reasons to postpone or decline treatment in the intervention group included having no symptoms $(n=4 ; 24 \%)$, concerns about side effects $(n=3 ; 18 \%)$, financial problems $(n=3 ; 17 \%)$, insufficient knowledge about $\operatorname{HCV}(n=3 ; 17 \%)$, doctor told treatment was not necessary $(n=2 ; 12 \%)$, and still injecting or using drugs $(n=2 ; 12 \%)$. In the control group reasons to refuse treatment at baseline were insufficient knowledge about $\operatorname{HCV}(n=5 ; 42 \%)$, having no symptoms ( $n=2 ; 17 \%)$, still injecting or using drugs $(n=2 ; 17 \%)$, financial problems $(n=1 ; 8 \%)$, other more important medical problems $(n=1 ; 8 \%)$ and other reasons $(n=1 ; 8 \%)$.

In the control group, $7 \%(n=2)$ of the participants gave a blood sample for screening in comparison to $20 \%(n=5)$ in the intervention group $(p=0,41)$. Four percent $(n=1)$ of the intervention group went to the hepatologist after the HCV screening and FibroScan and started treatment while no one of the control group saw a hepatologist $(p=1)$.

According to the sensitivity analysis to control for missing data regarding willingness for screening and treatment, there were no significant differences (all the $p$ values were $>0,05$ ) at the three time points (at baseline, 1 month after and 3 months after) between the control and the intervention groups for both situations.

\section{DISCUSSION}

This manuscript describes the first controlled study to combine formal and peer education with FibroScan measurement to increase HCV specific knowledge, screening and treatment uptake.

Knowledge of modifiable factors affecting HCV-related liver disease progression was low and HCV knowledge scores at baseline were mid-range as already described by Treloar et al. (Treloar, Hull, Dore, \& Grebely, 2012). It is alarming that most participants thought that there is a vaccine available to prevent HCV infection (65\%) and that the treatment for hepatitis C viral infection has to be followed lifelong (41\%). Knowledge scores were comparable to the studies of Surjadi et al. (Surjadi, et al., 
2011) and Gupta et al. (Gupta, et al., 2007). Any differences can be explained by the different questioning methods, namely multiple choice or true/false (Surjadi, et al., 2011) or attendance at the hepatology clinic (Gupta, et al., 2007).

Some of the questions that were answered incorrectly by the majority of our participants, were misunderstood. The question 'Hepatitis C is mainly spread by unprotected sex' was sometimes misunderstood as if unprotected sex was a possibility to contract hepatitis $C$ rather than being the main source of hepatitis C. Additionally, the question 'If you have hepatitis $C$, it is not necessary to get a vaccination for hepatitis A or B' was difficult to understand because of the negation in the sentence.

Knowledge scores were comparable at baseline between the control and intervention groups ( $58 \%$ vs. $59 \%$ ). The information session increased the knowledge scores by $27 \%$ in the intervention group and this knowledge was retained up to one month after the information session. However, knowledge scores decreased significantly after 3 months, which could indicate that the information session should be repeated regularly. Knowledge scores also improved non-significantly in the control group when baseline scores were compared with the scores one month after the information session. This can be explained by the fact that the participants discussed the questionnaire after completion and asked for information when they didn't agree.

When comparing the improvement in knowledge scores in our study (27\%) to the study by Surjadi et al. (Surjadi, et al., 2011) (14\%) and Gupta et al. (Gupta, et al., 2007) (15,8\%), it is clear that our method achieved a greater increase in knowledge. This could be explained by the more individual approach in our study compared to Surjadi et al. (Surjadi, et al., 2011), or by the longer information session in our study compared to Gupta et al. (Gupta, et al., 2007) which only lasted for 20 minutes.

While willingness for HCV screening improved slightly in the intervention group one month after the information session, willingness for HCV screening decreased in the control group. Fewer participants than expected filled in this questionnaire due to incarceration, deaths and hospital or psychiatric admissions.

The study of $\mathrm{Ti}$ et al. (Ti, et al., 2013) found that peer education was a factor that was statistically significantly associated with HCV screening. Also, in the study of Grebely et al. (Grebely, et al., 2010) in which a weekly support group with peers was organized, $53 \%$ of the patients underwent HCV 
assessment. This is much higher than in our study where after one session only $20 \%$ of the intervention group asked for HCV screening.

Reasons for refusing treatment varied but were consistent with the study by Grebely et al. (Grebely \& Dore, 2011). Different reasons to decline or postpone treatment were reported by the participants such as no symptoms, concerns about side effects, financial problems, insufficient knowledge about HCV, a previously consulted doctor told them treatment was not necessary, currently injecting or using drugs and the presence of other more important medical problems. Concerning financial problems, almost all CAD clients are insured and if not than health insurance is arranged for the clients. In the case that a patient is eligible for treatment, after assessment by the hepatologist, a large part of the cost of HCV treatment is reimbursed and a small amount is paid by the patients. But if these patients have financial problems than paying even a little amount themselves is not possible and they might delay or not start treatment at all.

One person in the intervention group started treatment before the end of this study, which is consistent with $2 \%$ of total participants and $4 \%$ of the intervention group.

These results indicate that there might be other important reasons, besides lack of knowledge, not to undergo screening or start treatment for HCV infection. A study by Swan et al. investigated the barriers for HCV care in injecting drug users and found that the absence of noticeable symptoms can result in a low perceived need for treatment. Also unstable housing, lack of transportation, poverty and social stigma complicate $\mathrm{HCV}$ care. Motivators for $\mathrm{HCV}$ treatment were becoming symptomatic, responsibilities for children and wanting to move on from drug use. (Swan, et al., 2010)

Based on the available literature, Robaeys et al published recommendations for the management of HCV in PWID. (Robaeys, et al., 2013) They recommended the use of a non-invasive liver fibrosis assessment because it can enhance liver disease screening. (Foucher, et al., 2009; Moessner, et al., 2011) These guidelines (Robaeys, et al., 2013) also recommended that pre-therapeutic education should include discussions about HCV transmission, risk factors for fibrosis progression, treatment, reinfection risk, and harm reduction strategies because poor HCV knowledge and inaccurate perceptions are barriers for accessing care. (Doab, Treloar, \& Dore, 2005; Grebely, et al., 2008; Treloar, et al., 2011; Treloar, Newland, Rance, \& Hopwood, 2010) In 2014 a study by Treloar et al suggested that particularly among PWID who feel well/ without symptoms non-invasive ways of liver 
damage assessment may facilitate entry into HCV care. (Treloar, Rance, Dore, Grebely, \& Group, 2014) Despite these guidelines and evidence encouraging to increase awareness of HCV infection and the use of non-invasive liver disease assessment, there are no governmental efforts, even in several developed western countries.

There were some limitations to this study: a small number of participants reached the end of follow-up (resulting in an underpowered study) and the follow-up period (3 months) was short. This study was a pilot to check the feasibility of the approach and to get preliminary results in this diverse population in order to start a larger project. Due to the small sample size and practical considerations only two groups, a control and intervention group, were studied. Therefore, no individual effects of education by provider, peer education and FibroScan could be compared with the standard of care. During the study period 24 participants left the OST program. Some of these participants might have received HCV screening and treatment in another health care setting. In the future with a larger study population the willingness for screening and treatment could be studied with multiple intervention groups (e.g. information session with or without FibroScan, a group who receives only a FibroScan, etc.).

During this study we noticed that participants, who received the intervention, were very positive about the information sessions with peer education in combination with a FibroScan. In the future regular repetition of short and simple information sessions with essential information are recommended. An incentive like cake or pastries for the participants together with a fun and interactive presentation helps to motivate them to listen to the information and is highly appreciated. With a few adjustments, this intervention might be a good method to educate this population about HCV infection.

In the PWUD population good guidance towards HCV testing and treatment is essential. In our opinion it would be very helpful if a nurse or care worker, who they trust and has regular contact with these patients, would motivate them towards screening and treatment, take blood samples, advocate for consultations with the hepatologist and support them during treatment. This population needs a lot of attention and personalized care for their mental and physical health.

In the future there is a need to perform a larger study with a longer follow-up period to investigate the effect of interventions such as education on HCV, peer education, FibroScan, involvement of nurses or other care takers in guiding patients through the whole process of screening and treatment. The results of these future studies can be used to improve HCV care. 


\section{CONCLUSION}

When interpreting the results and conclusions of this study, it is important to consider the small sample size and short follow-up period of this pilot project. The results of this pilot study suggest that one single information session significantly improves HCV knowledge. However, this does not lead to a higher uptake of screening and treatment as seen in previous studies. This could be a result of the limited impact of a single session or the short follow-up period in this study but it could also signify that there are other important reasons, besides lack of knowledge, not to undergo screening or start treatment. The fact that knowledge decreases after 3 months indicates that one session might not be sufficient and that it might be beneficial to repeat the information session more regularly.

\section{ACKNOWLEDGEMENTS}

This study is part of the 'Limburg Clinical Research Program (LCRP) UHasselt-ZOL-Jessa', supported by the foundation Limburg Sterk Merk, province of Limburg, Flemish government, Hasselt University, Ziekenhuis Oost-Limburg and Jessa Hospital. 


\section{REFERENCES}

Afdhal, N. H., Bacon, B. R., Patel, K., Lawitz, E. J., Gordon, S. C., Nelson, D. R., Challies, T. L., Nasser, I., Garg, J., Wei, L. J., \& McHutchison, J. G. (2014). Accuracy of Fibroscan, Compared with Histology, in Analysis of Liver Fibrosis in Patients with Hepatitis B or C: A US Multi-center Study. Clin Gastroenterol Hepatol.

Beste, L. A., Straits-Troster, K., Zickmund, S., Larson, M., Chapko, M., \& Dominitz, J. A. (2009). Specialty care and education associated with greater disease-specific knowledge but not satisfaction with care for chronic hepatitis C. Aliment Pharmacol Ther, 30, 275-282.

Cacoub, P., Ouzan, D., Melin, P., Lang, J. P., Rotily, M., Fontanges, T., Varastet, M., Chousterman, M., \& Marcellin, P. (2008). Patient education improves adherence to peg-interferon and ribavirin in chronic genotype 2 or 3 hepatitis C virus infection: a prospective, real-life, observational study. World J Gastroenterol, 14, 6195-6203.

Denniston, M. M., Klevens, R. M., McQuillan, G. M., \& Jiles, R. B. (2012). Awareness of infection, knowledge of hepatitis $C$, and medical follow-up among individuals testing positive for hepatitis C: National Health and Nutrition Examination Survey 2001-2008. Hepatology, 55, 1652-1661.

Doab, A., Treloar, C., \& Dore, G. J. (2005). Knowledge and attitudes about treatment for hepatitis C virus infection and barriers to treatment among current injection drug users in Australia. Clin Infect Dis, 40 Suppl 5, S313-320.

Edlin, B. R., Kresina, T. F., Raymond, D. B., Carden, M. R., Gourevitch, M. N., Rich, J. D., Cheever, L. W., \& Cargill, V. A. (2005). Overcoming barriers to prevention, care, and treatment of hepatitis C in illicit drug users. Clin Infect Dis, 40 Suppl 5, S276-285.

Foucher, J., Reiller, B., Jullien, V., Leal, F., di Cesare, E. S., Merrouche, W., Delile, J. M., \& de Ledinghen, V. (2009). FibroScan used in street-based outreach for drug users is useful for hepatitis $C$ virus screening and management: a prospective study. J Viral Hepat, 16, 121-131.

Fusfeld, L., Aggarwal, J., Dougher, C., Vera-Llonch, M., Bubb, S., Donepudi, M., \& Goss, T. F. (2013). Assessment of motivating factors associated with the initiation and completion of treatment for chronic hepatitis C virus (HCV) infection. BMC Infect Dis, 13, 234.

Geibel, S., King'ola, N., Temmerman, M., \& Luchters, S. (2012). The impact of peer outreach on HIV knowledge and prevention behaviours of male sex workers in Mombasa, Kenya. Sex Transm Infect, 88, 357-362.

Grebely, J., \& Dore, G. J. (2011). What is killing people with hepatitis C virus infection? Semin Liver Dis, 31, 331-339.

Grebely, J., Genoway, K. A., Raffa, J. D., Dhadwal, G., Rajan, T., Showler, G., Kalousek, K., Duncan, F., Tyndall, M. W., Fraser, C., Conway, B., \& Fischer, B. (2008). Barriers associated with the treatment of hepatitis C virus infection among illicit drug users. Drug Alcohol Depend, 93, 141147.

Grebely, J., Knight, E., Genoway, K. A., Viljoen, M., Khara, M., Elliott, D., Gallagher, L., Storms, M., Raffa, J. D., DeVlaming, S., Duncan, F., \& Conway, B. (2010). Optimizing assessment and treatment for hepatitis $\mathrm{C}$ virus infection in illicit drug users: a novel model incorporating multidisciplinary care and peer support. Eur J Gastroenterol Hepatol, 22, 270-277.

Gupta, K., Romney, D., Briggs, M., \& Benker, K. (2007). Effects of a brief educational program on knowledge and willingness to accept treatment among patients with hepatitis $\mathrm{C}$ at inner-city hospitals. J Community Health, 32, 221-230.

Larrey, D., Salse, A., Ribard, D., Boutet, O., Hyrailles-Blanc, V., Niang, B., Pageaux, G. P., Vaucher, E., Arpurt, J. P., Boulay, G., Karlova, N., \& Daures, J. P. (2011). Education by a nurse increases response of patients with chronic hepatitis $C$ to therapy with peginterferon-alpha2a and ribavirin. Clin Gastroenterol Hepatol, 9, 781-785.

Lubega, S., Agbim, U., Surjadi, M., Mahoney, M., \& Khalili, M. (2013). Formal hepatitis C education enhances HCV care coordination, expedites HCV treatment and improves antiviral response. Liver Int, 33, 999-1007.

Mateu-Gelabert, P., Gwadz, M. V., Guarino, H., Sandoval, M., Cleland, C. M., Jordan, A., Hagan, H., Lune, H., \& Friedman, S. R. (2014). The staying safe intervention: training people who inject drugs in strategies to avoid injection-related HCV and HIV infection. AIDS Educ Prev, 26, 144157.

Mehta, S. H., Genberg, B. L., Astemborski, J., Kavasery, R., Kirk, G. D., Vlahov, D., Strathdee, S. A., \& Thomas, D. L. (2008). Limited uptake of hepatitis $C$ treatment among injection drug users. J Community Health, 33, 126-133. 
Moessner, B. K., Jorgensen, T. R., Skamling, M., Vyberg, M., Junker, P., Pedersen, C., \& Christensen, P. B. (2011). Outreach screening of drug users for cirrhosis with transient elastography. Addiction, 106, 970-976.

Nyamathi, A., Tyler, D., Sinha, K., Marfisee, M., Cohen, A., \& Greengold, B. (2010). Predictors of hepatitis knowledge improvement among methadone maintained clients enrolled in a hepatitis intervention program. J Community Health, 35, 423-432.

Proeschold-Bell, R. J., Hoeppner, B., Taylor, B., Cohen, S., Blouin, R., Stringfield, B., \& Muir, A. J. (2011). An interrupted time series evaluation of a hepatitis $C$ intervention for persons with HIV. AIDS Behav, 15, 1721-1731.

Robaeys, G., Grebely, J., Mauss, S., Bruggmann, P., Moussalli, J., De Gottardi, A., Swan, T., Arain, A., Kautz, A., Stover, H., Wedemeyer, H., Schaefer, M., Taylor, L., Backmund, M., Dalgard, O., Prins, M., \& Dore, G. J. (2013). Recommendations for the management of hepatitis C virus infection among people who inject drugs. Clin Infect Dis, 57 Suppl 2, S129-137.

Roose, R. J., Cockerham-Colas, L., Soloway, I., Batchelder, A., \& Litwin, A. H. (2014). Reducing barriers to hepatitis $C$ treatment among drug users: an integrated hepatitis $C$ peer education and support program. $J$ Health Care Poor Underserved, 25, 652-662.

Shah, H. A., \& Abu-Amara, M. (2013). Education provides significant benefits to patients with hepatitis B virus or hepatitis C virus infection: a systematic review. Clin Gastroenterol Hepatol, 11, 922933.

Skipper, C., Guy, J. M., Parkes, J., Roderick, P., \& Rosenberg, W. M. (2003). Evaluation of a prison outreach clinic for the diagnosis and prevention of hepatitis $\mathrm{C}$ : implications for the national strategy. Gut, 52, 1500-1504.

Solomon, S. S., Mehta, S. H., Srikrishnan, A. K., Solomon, S., McFall, A. M., Laeyendecker, O., Celentano, D. D., Iqbal, S. H., Anand, S., Vasudevan, C. K., Saravanan, S., Lucas, G. M., Kumar, M. S., Sulkowski, M. S., \& Quinn, T. C. (2015). Burden of hepatitis C virus disease and access to hepatitis $C$ virus services in people who inject drugs in India: a cross-sectional study. Lancet Infect Dis, 15, 36-45.

Surjadi, M., Torruellas, C., Ayala, C., Yee, H. F., Jr., \& Khalili, M. (2011). Formal patient education improves patient knowledge of hepatitis C in vulnerable populations. Dig Dis Sci, 56, 213-219.

Swan, D., Long, J., Carr, O., Flanagan, J., Irish, H., Keating, S., Keaveney, M., Lambert, J., McCormick, P. A., McKiernan, S., Moloney, J., Perry, N., \& Cullen, W. (2010). Barriers to and facilitators of hepatitis $C$ testing, management, and treatment among current and former injecting drug users: a qualitative exploration. AIDS Patient Care STDS, 24, 753-762.

Ti, L., Kaplan, K., Hayashi, K., Suwannawong, P., Wood, E., \& Kerr, T. (2013). Low rates of hepatitis C testing among people who inject drugs in Thailand: implications for peer-based interventions. $\checkmark$ Public Health (Oxf), 35, 578-584.

Treloar, C., Hull, P., Bryant, J., Hopwood, M., Grebely, J., \& Lavis, Y. (2011). Factors associated with hepatitis $\mathrm{C}$ knowledge among a sample of treatment naive people who inject drugs. Drug Alcohol Depend, 116, 52-56.

Treloar, C., Hull, P., Dore, G. J., \& Grebely, J. (2012). Knowledge and barriers associated with assessment and treatment for hepatitis $C$ virus infection among people who inject drugs. Drug Alcohol Rev, 31, 918-924.

Treloar, C., Newland, J., Rance, J., \& Hopwood, M. (2010). Uptake and delivery of hepatitis C treatment in opiate substitution treatment: perceptions of clients and health professionals. $J$ Viral Hepat, 17, 839-844.

Treloar, C., Rance, J., Dore, G. J., Grebely, J., \& Group, E. S. (2014). Barriers and facilitators for assessment and treatment of hepatitis $C$ virus infection in the opioid substitution treatment setting: insights from the ETHOS study. $J$ Viral Hepat, 21, 560-567.

Zeremski, M., Dimova, R. B., Zavala, R., Kritz, S., Lin, M., Smith, B. D., Zibbell, J. E., \& Talal, A. H. (2014). Hepatitis $C$ virus-related knowledge and willingness to receive treatment among patients on methadone maintenance. J Addict Med, 8, 249-257. 
Table 1: Characteristics of the study population

\begin{tabular}{|c|c|c|c|}
\hline Characteristics & Control group & Intervention group & Total \\
\hline \multirow{4}{*}{$\begin{array}{l}\text { Age mean } \pm \text { SD (years) } \\
\text { Males (\%) } \\
\text { Belgian origin (\%) } \\
\text { Education (\%) }\end{array}$} & $40 \pm 9$ & $38 \pm 9$ & $39 \pm 8$ \\
\hline & $20 / 27(74 \%)$ & $20 / 25(80 \%)$ & 40/52 (77\%) \\
\hline & $15 / 27(56 \%)$ & $19 / 25(76 \%)$ & $34 / 52(65 \%)$ \\
\hline & & & \\
\hline \multirow{4}{*}{$\begin{array}{l}\text { None } \\
\text { Primary school } \\
\text { Secondary school } \\
\text { Higher education }\end{array}$} & $5 / 27(19 \%)$ & $6 / 25(24 \%)$ & $11 / 52(21 \%)$ \\
\hline & $7 / 27(26 \%)$ & $4 / 25(16 \%)$ & $11 / 52(21 \%)$ \\
\hline & $15 / 27(56 \%)$ & $12 / 25(48 \%)$ & $27 / 52(52 \%)$ \\
\hline & 0 & $3 / 25(12 \%)$ & $3 / 52(6 \%)$ \\
\hline \multicolumn{4}{|l|}{ Source of income (\%) } \\
\hline No income & $2 / 27(7 \%)$ & $2 / 25(8 \%)$ & $4 / 52(8 \%)$ \\
\hline \multirow{2}{*}{ Full/part time job } & $3 / 27(11 \%)$ & $3 / 25(12 \%)$ & $6 / 52(12 \%)$ \\
\hline & $17 / 27(63 \%)$ & $16 / 25(64 \%)$ & $33 / 52(63 \%)$ \\
\hline Other & $5 / 27(19 \%)$ & $4 / 25(16 \%)$ & $9 / 52(17 \%)$ \\
\hline \multirow{2}{*}{$\begin{array}{l}\text { Monthly income (EUR) } \\
\text { Living alone (\%) }\end{array}$} & $977 \pm 369$ & $938 \pm 390$ & $959 \pm 375$ \\
\hline & $16 / 27(59 \%)$ & $14 / 25(56 \%)$ & $30 / 52(58 \%)$ \\
\hline \multicolumn{4}{|l|}{ Housing (\%) } \\
\hline Homeless & $3 / 25(12 \%)$ & $2 / 25(8 \%)$ & $5 / 50(10 \%)$ \\
\hline Own property house/flat & $3 / 25(12 \%)$ & $1 / 25(4 \%)$ & $4 / 50(8 \%)$ \\
\hline Rented house/flat & $15 / 25(60 \%)$ & $19 / 25(76 \%)$ & $34 / 50(68 \%)$ \\
\hline Social housing & $1 / 25(4 \%)$ & $3 / 25(12 \%)$ & $4 / 50(8 \%)$ \\
\hline Other & $3 / 25(12 \%)$ & 0 & $3 / 50(6 \%)$ \\
\hline \multirow{2}{*}{$\begin{array}{l}\text { Liver transplant }(\%) \\
\text { HCV risk factors (\%) }\end{array}$} & 0 & 0 & 0 \\
\hline & \multicolumn{3}{|c|}{ HCV risk factors (\%) } \\
\hline \multirow{3}{*}{$\begin{array}{l}\text { Ever used IV drugs } \\
\text { IV drug use in last } 3 \text { months } \\
\text { Sharing equipment }\end{array}$} & $15 / 26(58 \%)$ & $20 / 25(80 \%)$ & $35 / 51(69 \%)$ \\
\hline & $6 / 17(35 \%)$ & $12 / 20(60 \%)$ & $18 / 37(49 \%)$ \\
\hline & & & \\
\hline \multirow{2}{*}{$\begin{array}{l}\text { Needles or syringes } \\
\text { spoons/ cookers }\end{array}$} & $3 / 16(19 \%)$ & $4 / 20(20 \%)$ & $7 / 36(19 \%)$ \\
\hline & $3 / 15(20 \%)$ & $3 / 20(15 \%)$ & $6 / 35(17 \%)$ \\
\hline Filters & $4 / 15(27 \%)$ & $3 / 20(15 \%)$ & $7 / 35(20 \%)$ \\
\hline Tourniquets & $4 / 15(27 \%)$ & $4 / 20(20 \%)$ & $8 / 35(23 \%)$ \\
\hline \multirow{2}{*}{$\begin{array}{c}\text { Water } \\
\text { Tattooed (\%) }\end{array}$} & $4 / 15(27 \%)$ & $6 / 20(30 \%)$ & $10 / 35(29 \%)$ \\
\hline & $20 / 27(74 \%)$ & $15 / 25(60 \%)$ & $35 / 52$ (67\%) \\
\hline \multirow{2}{*}{$\begin{array}{l}\text { Blood transfusion (\%) } \\
\text { Incarceration (\%) }\end{array}$} & $8 / 27(30 \%)$ & $2 / 25(8 \%)$ & $10 / 52(19 \%)$ \\
\hline & $24 / 27(89 \%)$ & $20 / 25$ (80\%) & $44 / 52(85 \%)$ \\
\hline \multicolumn{4}{|l|}{ Sexual orientation (\%) } \\
\hline Heterosexual & $25 / 26(96 \%)$ & $23 / 25(92 \%)$ & 48/51 (94\%) \\
\hline Homosexual & 0 & 0 & 0 \\
\hline \multirow{2}{*}{$\begin{array}{l}\text { Bisexual } \\
\text { I don't know }\end{array}$} & $1 / 26(4 \%)$ & $1 / 25(4 \%)$ & $2 / 51(4 \%)$ \\
\hline & 0 & $1 / 25(4 \%)$ & $1 / 52(2 \%)$ \\
\hline
\end{tabular}


Table 2: HCV knowledge at baseline in control and intervention group.

\section{TRUE/FALSE QUESTIONS}

1. Hepatitis $C$ is caused by a virus

2. Hepatitis $C$ is spread by sharing needles for drugs

3. Hepatitis $C$ is mainly spread by unprotected sex

4. A person can get hepatitis $C$ by getting a tattoo or piercing

5. A person can get hepatitis $C$ by sharing personal material like razors or tooth brushes

6 . To be certain of a hepatitis $C$ infection, a blood test is necessary

7. Hepatitis $C$ damages the liver and can cause liver failure

8. Hepatitis $C$ can lead to liver cancer

9. Some people can live many years without symptoms

10. Part of the people infected with the hepatitis $C$ virus can cure spontaneously

11. Drinking a lot of alcohol is a good idea for someone with hepatitis $\mathrm{C}$

12. There is a vaccine to prevent hepatitis $C$

13. The treatment for hepatitis $C$ cures everyone who is treated

14. The treatment for hepatitis $C$ currently consists of injections and taking pills

15. The treatment for hepatitis $C$ has to be taken lifelong

16. The treatment for hepatitis $C$ can cause side effects like depression

17. Substitution treatment can be followed during hepatitis $C$ treatment

18. Once you completed a treatment for hepatitis $C$, a reinfection is impossible because you're immune 19. If you have hepatitis $C$ it is not necessary to get a vaccination for hepatitis $A$ or $B$

TOTAL MEAN SCORE (\%)
CORRECT AT BASELINE (\%) Control Intervention Total

\begin{tabular}{|c|c|c|}
\hline 46 & 65 & 56 \\
\hline 85 & 89 & 87 \\
\hline 35 & 35 & 35 \\
\hline 62 & 62 & 62 \\
\hline 77 & 73 & 75 \\
\hline 81 & 77 & 79 \\
\hline 92 & 77 & 85 \\
\hline 81 & 50 & 65 \\
\hline 73 & 62 & 67 \\
\hline 27 & 23 & 25 \\
\hline 65 & 73 & 69 \\
\hline 39 & 31 & 35 \\
\hline 54 & 54 & 54 \\
\hline 42 & 65 & 56 \\
\hline 35 & 42 & 39 \\
\hline 62 & 62 & 62 \\
\hline 65 & 73 & 64 \\
\hline 65 & 58 & 62 \\
\hline 35 & 31 & 33 \\
\hline 58 & 59 & 59 \\
\hline
\end{tabular}




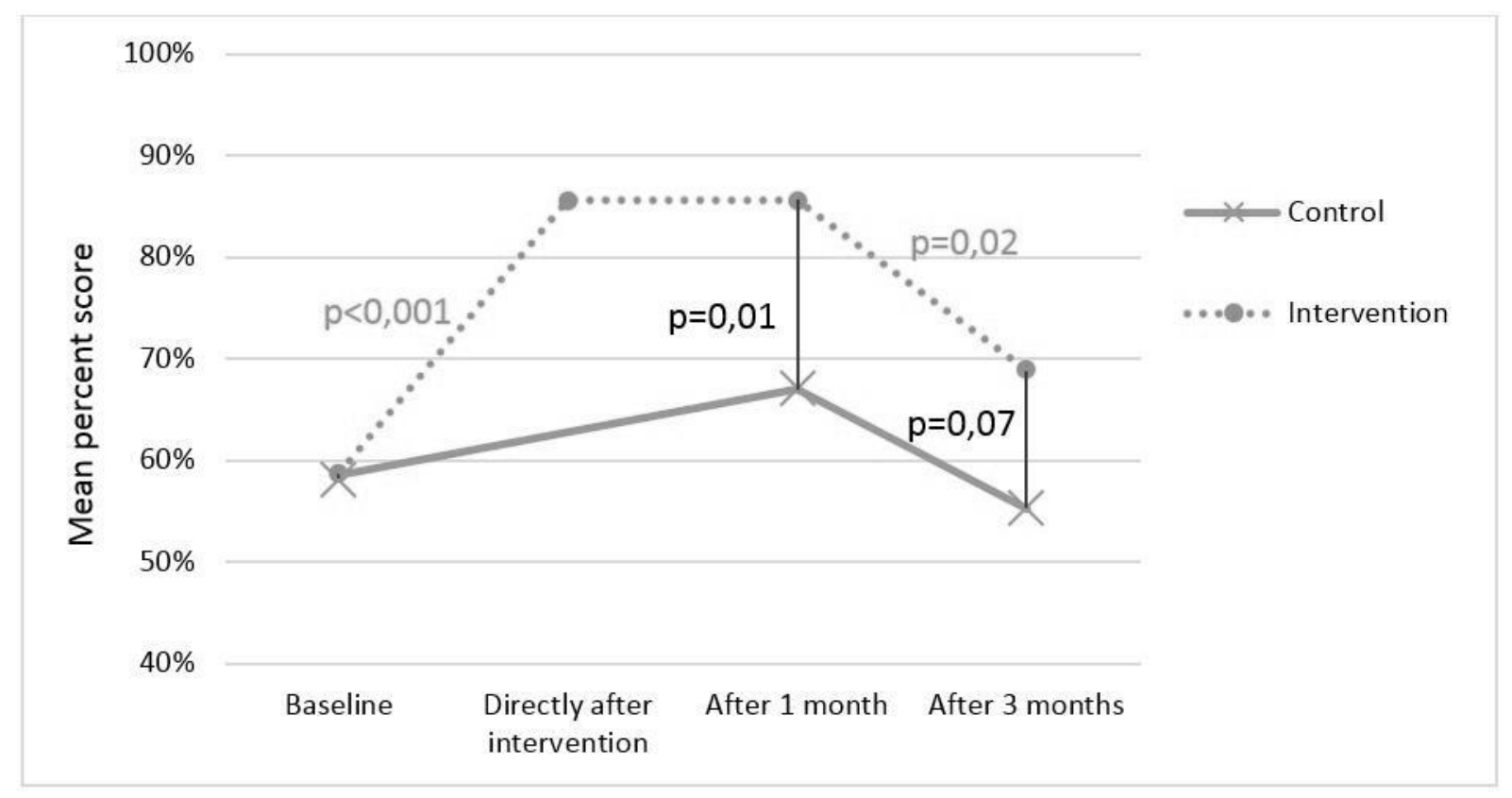

Figure 1: Change in mean percent knowledge scores across all time points.

Table 3: Willingness to undergo screening and treatment.

\begin{tabular}{|c|c|c|c|c|c|c|c|c|}
\hline \multirow[b]{2}{*}{$\begin{array}{l}\text { Willingness } \\
\text { for }\end{array}$} & \multicolumn{3}{|c|}{ CONTROL } & \multicolumn{5}{|c|}{ INTERVENTION } \\
\hline & $\begin{array}{c}\text { Baseline } \\
(n=27)\end{array}$ & $\begin{array}{c}\text { After } 1 \\
\text { month } \\
(n=9)\end{array}$ & $\begin{array}{c}\text { After } 3 \\
\text { months } \\
(n=6)\end{array}$ & $\begin{array}{c}\text { Baseline } \\
(\mathrm{n}=21)\end{array}$ & $\begin{array}{c}\text { After } \\
\text { info } \\
(n=23)\end{array}$ & $\begin{array}{c}\text { After } 1 \\
\text { month } \\
(n=8)\end{array}$ & $\begin{array}{c}\text { After } 3 \\
\text { months } \\
(n=13)\end{array}$ & $\begin{array}{c}\text { After } \\
\text { FibroScan } \\
(n=12)\end{array}$ \\
\hline \multirow{4}{*}{$\begin{array}{l}\text { Screening (\%) } \\
\text { Treatment (\%) } \\
\text { Yes } \\
\text { Yes, but not } \\
\text { now } \\
\text { No, never } \\
\end{array}$} & 89 & 56 & 67 & 86 & 96 & 100 & 77 & 100 \\
\hline & 81 & 44 & 50 & 81 & 87 & 75 & 85 & 75 \\
\hline & 15 & 56 & 50 & 10 & 9 & 25 & 8 & 8 \\
\hline & 4 & 0 & 0 & 9 & 4 & 0 & 7 & 17 \\
\hline
\end{tabular}

